\title{
Analysis of Product Complexity considering Disruption Cost in Fast Fashion Supply Chain
}

\author{
Shaheen Sardar and Young Hae Lee \\ Department of Industrial and Management Engineering, Hanyang University, Gyeonggi-do, Ansan 426-791, Republic of Korea \\ Correspondence should be addressed to Young Hae Lee; yhlee@hanyang.ac.kr
}

Received 28 May 2014; Revised 3 July 2014; Accepted 4 July 2014

Academic Editor: Tsan-Ming Choi

Copyright (C) 2015 S. Sardar and Y. H. Lee. This is an open access article distributed under the Creative Commons Attribution License, which permits unrestricted use, distribution, and reproduction in any medium, provided the original work is properly cited.

\begin{abstract}
Outsourcing in the textile industry has been playing an important role in the global economy for six decades. Recently, reshoring is an emerging trend due to various complexities involved in supply chain management. As compared with basic textile and apparel products, fast fashion products are complex in their own way. A single assortment contains several new styles, colors, and sizes with unpredictable demand and urgent deadlines. Numerous assortments run simultaneously in the supply chain. For each assortment, the garment manufacturer has to source various types of fabrics and materials from different suppliers and then manufacture the garments to ship within the deadlines. This complexity contributes to supply chain disruption. This paper develops a model to estimate supply chain disruption cost as a function of fast fashion product complexity in the global outsourcing environment. Estimation of disruption cost will help us to increase visibility and eliminate the bottlenecks in supply chain. Model conclusions are used to develop a method to manage the level of product complexity from the global supply chain perspective. Several strategies are proposed to manage the impact of product complexity on supply chain design.
\end{abstract}

\section{Introduction}

Textile supply chain has a complex structure due to independently separated divisions and a sequence of complicated processes required in each division $[1,2]$. Time-consuming and labor intensive processes in textile supply chain create difficulty in synchronization of various activities and obstruct the implementation of modern supply chain management practices in this industry $[3,4]$. This complexity has caused recent research to avoid the investigation of textile supply chain management and has prevented the effective implementation of quick response strategy in textile supply chain $[4,5]$. The time a garment spent travelling through a pipeline, from fiber to retailer, was 66 weeks, and, of that, only 11 weeks was taken up with processing. The balance of over one year was storage time [6]. Supply chain complexity in the textile industry has caused the obstacles in coordination between suppliers, manufacturers, and retailers. In the textile and fashion supply chains, there is uneven distribution of financial benefits between manufacturer and retailer [7].
Except for the distribution portion of the textile and apparel products, the dependent portion of global chains is ineffective and inefficient due to nonoptimal inventories, lead times, transportation, and service levels [8]. Outsourcing in supply chain is a little researched topic, and there is a lack of perspective and practical models to express outsourcing decision processes, particularly for logistic activities of supply chain, so this category of supply chain management needs more attention to fill the research gaps [2, 4, 911]. Recently, reshoring is an emerging trend [11, 12] as a result of complexities involved in managing the dependent portion of the textile supply chain. This situation is making it difficult for textile companies to maintain competitive advantage in the global environment. Emergence of the fast fashion industry increased further complexity. Just as fast fashion has disrupted the traditional supply chain, changes are occurring within the fast fashion supply chain; Zara has extended its supply chain to outsource to Turkey [13]. There is a lack of literature which relates the product complexity with supply chain processes. Relatively little is known about 
complexity of products and its relation to manufacturing processes [14]. Existing product complexity methods lack the fact that complexity is a relative phenomenon arising between a product and a process and thus cannot be assessed meaningfully with regard to the product and its properties [15]. Novak and Eppinger [16] found a significant connection between product complexity and vertical integration. Product complexity has a direct impact on supply chain performance [17]. There appears to be a gap in the supply chain research literature regarding the impact of a product's complexity [18]. Few studies have suggested a correlation between supply chain management decisions and the level of product complexity [19]. Impact of product design complexity on supply chain performance has been widely ignored. Impact of product design complexity on supply chain risk is even more significant in industries, such as fashion, where product design is a competitive advantage [20,21].

Academic research on fast fashion retailers is an emerging field of study [13]. Most of the existing studies on the fast fashion supply chain are empirical and case based in nature [22]. Choi [13] performed a rigorous literature review related to fast fashion supply chain management and concluded "much of supply chain management literature about fast fashion is exploratory in nature (usually qualitative interviews and case study approach) and provides information about topics such as the role of buying and sourcing, inventory management, category management, and RFID implementation.” Analytical models are still mainly in the trial phase. To the knowledge of the authors of this paper, no quantitative study exists to model and manage the impact of fast fashion product complexity from the supply chain point of view. Without understanding the realized costs of complexity, efficient means to reduce the future costs of complexity cannot be defined [15]. If we ignore this issue, it can cause uncontrollable disruptions in terms of inventory obsolescence, much higher stocks, unreliable deliveries, economic crisis, and loss of competitiveness in the global textile and apparel supply chain. The key aim of this paper is to propose a model of fast fashion product complexity for managing the supply chain disruption in the global outsourcing environment. To achieve this aim, this paper makes the following contributions to the existing literature.

(i) Identify key factors which contribute to product complexity in the fast fashion supply chain.

(ii) Identify key types of cost of product complexity/disruption in the fast fashion supply chain.

(iii) Estimate supply chain disruption cost as a function of product complexity in the global outsourcing environment. This will increase the supply chain visibility through proper tracking of disruption cost.

(iv) Adjust the level of product complexity associated with surplus (existing and novel) elements of product complexity, degree of novelty in an assortment, and number of assortments running in the supply chain.
TABLE 1: Key factors contributing to product complexity.

\begin{tabular}{ll}
\hline Number & Factors \\
\hline 1 & Variety of sizes \\
2 & Variety of designs \\
3 & Variety of materials \\
4 & Variety of products \\
5 & Variety of processes \\
6 & Variety of components \\
7 & Product modularity \\
8 & Number of parts or components needed to build \\
9 & the product \\
10 & Difficulty of generating different parts \\
11 & Interactions between parts or components \\
12 & Degree of product novelty/newness \\
13 & Production volume of running products \\
14 & Degree of order within the structure of elements \\
\hline
\end{tabular}

(v) Several strategies are proposed for managing the impact of product complexity for effective supply chain design.

\section{Related Literature and Conceptual Framework}

2.1. Fast Fashion Supply Chains. Fast fashion supply chain is the type of fashion apparel supply chain that refers to the concept of shortening the lead time (production, distribution, etc.) and offering new products to the market as fast as possible [13]. Firms in the fashion apparel industry-such as Zara, H\&M, and Benetton-have increasingly embraced the philosophy of "fast fashion" retailing. Thus, fast fashion incorporates two core features, namely, (1) quick response (and short lead time) in terms of inventory management and (2) enhanced fashion design $[22,23]$. Therefore, product complexity in the fast fashion supply chain can be evaluated with the help of product characteristics and their relation to the supply chain processes.

2.2. Product Complexity. Table 1 summarizes several aspects of product complexity identified in the existing literature [16-20, 24-26]. These factors contribute to the supply chain complexity.

Our focus is to realize the impact of product complexity on supply chain design, and we do not investigate each aspect of supply chain disruption cost, which is a much broader field. In this paper, we restrict our definition of disruption cost as "there are some key types of cost of product complexity in supply chain, and an increase in product complexity is causing the excessive increase in frequency or amount of these costs resulting in disruption cost." Here, disruption factor can be introduced. Disruption factor can be expressed as ratio of the frequency of disruption (probable) to the frequency of cost of product complexity (already understood). Hence, 
TABLE 2: Key costs of product complexity.

\begin{tabular}{ll}
\hline Number & Cost \\
\hline 1 & Material cost \\
2 & Manufacturing cost \\
3 & Overhead \\
4 & Inventory costs \\
5 & Distribution cost \\
6 & Extra labor hours \\
7 & Set-ups \\
8 & Reduction in capacity \\
9 & Capital equipment \\
10 & Training cost \\
11 & Cost of quality \\
12 & Process investments \\
13 & Procurement cost \\
14 & Delivery performance cost \\
15 & Frequent product development cost \\
16 & Learning curve losses \\
17 & Logistic cost \\
18 & IT system cost \\
19 & Balancing assembly lines cost \\
20 & Production scheduling cost \\
21 & Loss of economies of scale cost \\
\hline
\end{tabular}

disruption factor can be used to determine the frequency of disruption as "multiplicative of the frequency of cost of product complexity." Table 2 summarizes the key costs of product complexity highlighted in existing literature $[15,19$, $25,27,28]$. Disruption cost is different from cost of product complexity in the sense that "cost of product complexity is understood, but disruption cost occurred unexpectedly."

2.3. Fast Fashion Product Complexity. The problems associated with fashion merchandise are more complex than those with basic merchandise and require sophisticated analysis of fashion and color trends $[29,30]$. When the "fashion" becomes "fast fashion," it increases further complexity. Fast fashion products seem more simple than automotive and computer products, but different sizes, colors, styles, and other attributes increase the complexity of fashion products in unique way. Key components of fast fashion systems include a quick response policy (to reduce lead time); product assortment (which changes quickly); product life cycle (very short); and product design (which fits the fashion trend and market need). Fast fashion is a term used to describe practices employed by several global retailers in which merchandise assortments are adapted to "current and emerging trends as quickly as possible" [13]. In the case of the fast fashion industry, the manufacturer is always under pressure from retailers as well as fabric and materials suppliers. To decrease the burden of managing thousands of items with different colors and sizes, companies outsource to domestic markets as well as international markets. There is strong evidence that the fast fashion industry has become globalized in nature. Globalization has been an important development and the outsourcing of fashion products is also an integral part of the world of fast fashion industry [31].

Zara (i.e., fast fashion retailer) brings 11000 different items annually (with 5-6 colors and 5-7 sizes), and H\&M (i.e., fast fashion retailer) brings 2000-4000 different items annually in the consumer markets. Despite its own facilities in home country, Zara is leaning toward international outsourcing. Producing so many styles for such a large number of stores necessitates having massive production facilities [13]. Other fast fashion retailers (e.g., H\&M), who do not own manufacturing facilities in their home country, create a strong environment for global competition. Joint decision making between suppliers, manufacturers, and retailers may not be much important for basic fashion and textile products. In case of fast fashion products, the retailer requires a specific technology to produce an innovative fashionable product, and the number of this kind of sellers is limited in the market [32]. Original functions of quick response system cannot completely overcome the challenges in the fashion supply chain [33]. The reality behind unsuccessful implementation of quick response strategy is the textile product complexity. Emergence of the fast fashion industry added further complexity. Therefore, fast fashion strategy should be comprised of both quick response policy and product complexity management. H\&M has 2653 stores in 54 countries, and Zara has 1972 stores in 89 countries. Globalization motivates the companies to keep manufacturing facilities as close as possible to the sales points. There is a huge difference of unit cost in the international textile and apparel markets which further accelerates the cost based competition. Labor accounts for about $50 \%$ of the total cost of garment $[2,11,34]$. Companies that outsource internationally focus on achieving cost benefits, while companies that outsource domestically focus on achieving capacity flexibility $[2,11,35]$.

In the clothing industry, product complexity is concerned with collection and assortment [36]. In this paper, we define an assortment as "collection of different consumer products to be shipped to retailer simultaneously." In the fast fashion industry, managers deal with thousands of assortments with varying degrees of novelty. Much of the product complexity is embodied in the product at design stage. For example, if each new design has a unique bill of materials (BOM), then impact on inventory costs will be significant and will remain throughout the life of that product [37]. If the market information is revealed, the fashion retailer could make better production plan, such as deciding the clothing color, the raw material quality, the style, and the quantity. Large fashion companies often employ sales representatives to help the retailers for quick demand information [38]. In the fast fashion supply chains, if market information is not available on time, the manufacturer faces serious pressure from upstream suppliers and downstream retailers.

In summary, product design is a competitive advantage in the fast fashion industry; we can decrease frequency of cost of product complexity and excessive disruptions by effective management of (i) the number of elements of product complexity in an assortment; (ii) the number of assortments; and (iii) the degree of novelty in an assortment. Elements of product complexity represent the combination of parts 
TABLE 3: Fast fashion product complexity and resultant cost.

\begin{tabular}{|c|c|c|c|}
\hline \multirow{2}{*}{ Company category } & \multirow{2}{*}{$\begin{array}{l}\text { Product complexity based on } \\
\text { (i) number of elements of product complexity in an assortment; } \\
\text { (ii) number of assortments; (iii) degree of novelty in an assortment }\end{array}$} & \multicolumn{2}{|c|}{ Cost of product complexity } \\
\hline & & Types of cost & $\begin{array}{l}\text { Location of garment } \\
\text { manufacturer }\end{array}$ \\
\hline \multirow{4}{*}{ Fabric suppliers } & Number of fabric variants in all assortments & & \multirow{10}{*}{$\begin{array}{l}\text { (i) In-house in home } \\
\text { country } \\
\text { (ii) Domestic supplier } \\
\text { (iii) International } \\
\text { subsidiary } \\
\text { (iv) International } \\
\text { supplier }\end{array}$} \\
\hline & Number of novel fabric variants in all assortments & Premium freight & \\
\hline & Number of fabric colors in all assortments & & \\
\hline & Number of novel fabric colors in all assortments & & \\
\hline $\begin{array}{l}\text { Trims and accessories } \\
\text { suppliers }\end{array}$ & $\begin{array}{l}\text { Number of unique trims and accessories in all assortments } \\
\text { Number of novel unique trims and accessories in all assortments }\end{array}$ & Premium freight & \\
\hline \multirow{4}{*}{$\begin{array}{l}\text { Garment } \\
\text { manufacturer }\end{array}$} & Number of unique fabric cut parts in all assortments & \multirow{4}{*}{$\begin{array}{l}\text { Premium freight }+ \\
\text { set-up }+ \text { overtime }\end{array}$} & \\
\hline & Number of novel unique fabric cut parts in all assortments & & \\
\hline & Number of unique sewing operations in all assortments & & \\
\hline & Number of novel unique sewing operations in all assortments & & \\
\hline Retailer & $\begin{array}{l}\text { Average unsold percentage for an assortment is due to } \\
\text { (1) incorrect assortment planning and forecasting. } \\
\text { (2) disruptions occurred at upstream supply chain. }\end{array}$ & $\begin{array}{l}\text { Obsolescence + } \\
\text { holding }\end{array}$ & \\
\hline
\end{tabular}

and attributes of complexity. Company category is a specific category of company in which the average cost of the product complexity (or disruption) cost is almost the same for each turn/occurrence of cost.

Zara, the fast fashion company, produces each particular design only once; its production processes and product designs have to be flexible so that it can switch from producing one product to the next without incurring significant set-up time or set-up costs [39]. Kelley [40] highlighted two costs: cost of overstock and cost of understock at retailer level in fast fashion supply chain. Unsold merchandise accounts for $17-20 \%$ in overall fast fashion industry and less than $10 \%$ of stock for Zara [6]. Therefore, there is no scope for forecasting errors in the fast fashion supply chain systems. The demand forecasting function has to be completed within a very short period of time with very little historical data being available [41]. Due to forecasting inefficiencies and upstream disruptions, the overstocking at retail store results in inventory obsolescence and inventory holding cost. We do not use understock cost. In the fast fashion context, if some proper and active stock-out management schemes are adopted successfully, stock-out can encourage the consumer to purchase another item immediately [23]. In the fashion industry, products should be moved more quickly through the pipeline to reduce the risk of holding obsolete products [37]. Zara strategy to produce or source domestically helps to ensure the implementation of quick response strategy. Offshore outsourcing increases the disruption risk to an alarming level. To motivate the fast fashion companies to source domestically, the idea of implementation of carbon footprint tax would be more effective [42]. Premium freight is the additional charge paid to a transportation provider to expedite shipments in order to meet a required date [43]. Premium freight is common in fast industry. The fast fashion retailer Zara's practices of sending a half-empty truck across Europe, paying for airfreight twice a week to ship coats on hangers to Japan, or running factories for only one shift went against the usual principles of efficiency [44, 45]. Table 3 summarizes the above mentioned ideas.

\section{Estimation of Disruption Cost as a Function of Product Complexity}

Let us consider a three-echelon supply chain across the world (Figure 1). A garment manufacturer in a home country decides to outsource the manufacturing to different global destinations in order to take advantage of cost and capacity flexibility across the world. It purchases the materials from suppliers, allocates manufacturing at different global production destinations, and ships to the retailer [36]. Let us make some assumptions. All suppliers must fill delayed shipments with premium freight. The garment manufacturer must satisfy the retailer's full demand and fill delayed shipments with overtime or premium freight. Unsold inventory at a retail store becomes obsolete. Now, all members of the supply chain decide to estimate disruption cost in order to enhance visibility, highlight problematic areas, and adopt effective strategies to deal with product complexity.

Let

$i$ : index of assortments running in supply chain, $i=$ $1,2,3, \ldots, n$,

$j$ : index of manufacturing destinations across the globe, $j=1,2,3, \ldots, m$,

$\bar{x}_{a, j}$ : average cost per one turn/occurrence of premium freight for fabric suppliers at destination $j$,

$\bar{x}_{b, j}$ : average cost per one occurrence of premium freight for trims and accessories suppliers at destination $j$,

$\bar{x}_{c 1, j}$ : average cost per one occurrence of premium freight for garment manufacturer at destination $j$, 
$\bar{x}_{c 2, j}:$ average cost per one occurrence of overtime for garment manufacturer at destination $j$,

$\bar{x}_{c 3, j}$ : average cost per one occurrence of set-up for garment manufacturer at destination $j$,

$\left(d_{1}\right)_{i, j}$ : number of premium freight disruptions for fabric suppliers for assortment $i$ at destination $j$,

$\left(d_{2}\right)_{i, j}$ : number of premium freight disruptions for trims and accessories suppliers for assortment $i$ at destination $j$,

$\left(d_{3}\right)_{i, j}$ : number of premium freight disruptions for garment manufacturer for assortment $i$ at destination j,

$\left(d_{4}\right)_{i, j}$ : number of overtime disruptions for garment manufacturer for assortment $i$ at destination $j$,

$\left(d_{5}\right)_{i, j}$ : number of set-up disruptions for garment manufacturer for assortment $i$ at destination $j$,

$r$ : index of similar nature of premium freight disruptions occurred for fabric suppliers in past, $r=$ $1,2,3, \ldots, R$,

$k$ : index of similar nature of premium freight disruptions occurred for trims and accessories suppliers in past, $k=1,2,3, \ldots, K$,

$p$ : index of similar nature of premium freight disruptions occurred for garment manufacturer in past, $p=1,2,3, \ldots, P$,

$u$ : index of similar nature of overtime disruptions occurred for garment manufacturer in past, $u=$ $1,2,3, \ldots, U$,

$q$ : index of similar nature of set-up disruptions occurred for garment manufacturer in past, $q=$ $1,2,3, \ldots, Q$,

$\alpha_{r}$ : cost of premium freight disruption $r$ for fabric suppliers occurred in past,

$\beta_{k}$ : cost of premium freight disruption $k$ for trims and accessories suppliers occurred in past,

$\gamma_{p}$ : cost of premium freight disruption $p$ for garment manufacturer occurred in past,

$\delta_{u}$ : cost of overtime disruption $u$ for garment manufacturer occurred in past,

$\varepsilon_{q}$ : cost of set-up disruption $q$ for garment manufacturer occurred in past,

$l$ : hourly compensation or labor cost per hour,

$\tau$ : overtime allowance per hour,

$\mathfrak{h}$ : number of hours consumed per one occurrence of overtime,

$\mathfrak{R}$ : number of workers assigned to one occurrence of overtime,

$\omega$ : number of workers assigned to one occurrence of set-up,

$\mathfrak{T}$ : number of hours consumed on one occurrence of set-up,
$M_{i, j}$ : total cost of manufacturing for assortment $i$ at destination $j$,

t: transportation cost for an average garment,

$\mathbb{Z}$ : transaction cost for an average garment,

$a$ : percentage of unit production cost which is comprised of labor cost,

$\mathbb{N}_{i}$ : number of items in assortment $i$,

$O_{i, j}$ : inventory overstock cost for assortment $i$ due to destination $j$ for retailer,

$H_{i, j}$ : inventory holding cost for assortment $i$ due to destination $j$ for retailer,

$\varphi_{i, j}$ : percentage of assortment $i$ sold to consumers manufactured at destination $j$ for retailer,

th: inventory holding cost for obsolete stock for an average garment,

$E 1_{i}$ : number of elements of product complexity for fabric suppliers in assortment $i$,

$E 2_{i}$ : number of elements of product complexity for trims and accessories suppliers in assortment $i$,

$E 3_{i}$ : number of elements of product complexity for garment manufacturer in assortment $i$,

$f 1_{i}$ : frequency of occurrence of premium freight for fabric suppliers in assortment $i$,

$f 2_{i}$ : frequency of occurrence of premium freight for trims and accessories suppliers in assortment $i$,

$f 3_{i}$ : frequency of occurrence of premium freight for garment manufacturer in assortment $i$,

$f 4_{i}$ : frequency of occurrence of overtime for garment manufacturer in assortment $i$,

$f 5_{i}$ : frequency of occurrence of set-up for garment manufacturer in assortment $i$,

$\Omega_{1, j}$ : disruption factor without impact of assortments for premium freight for fabric suppliers at destination j,

$\Omega_{2, j}$ : disruption factor without impact of assortments for premium freight for trims and accessories suppliers at destination $j$,

$\Omega_{3, j}$ : disruption factor without impact of assortments for premium freight for garment manufacturer at destination $j$,

$\Omega_{4, j}$ : disruption factor without impact of assortments for overtime for garment manufacturer at destination j,

$\Omega_{5, j}$ : disruption factor without impact of assortments for set-up for garment manufacturer at destination $j$, $\exists 1_{i, j}$ : disruption factor with impact of assortments for premium freight disruptions for fabric suppliers for assortment $i$ at destination $j$.

There are hundreds of different kinds of fabrics, trims, and accessories which are sourced by garment manufacturers. It 


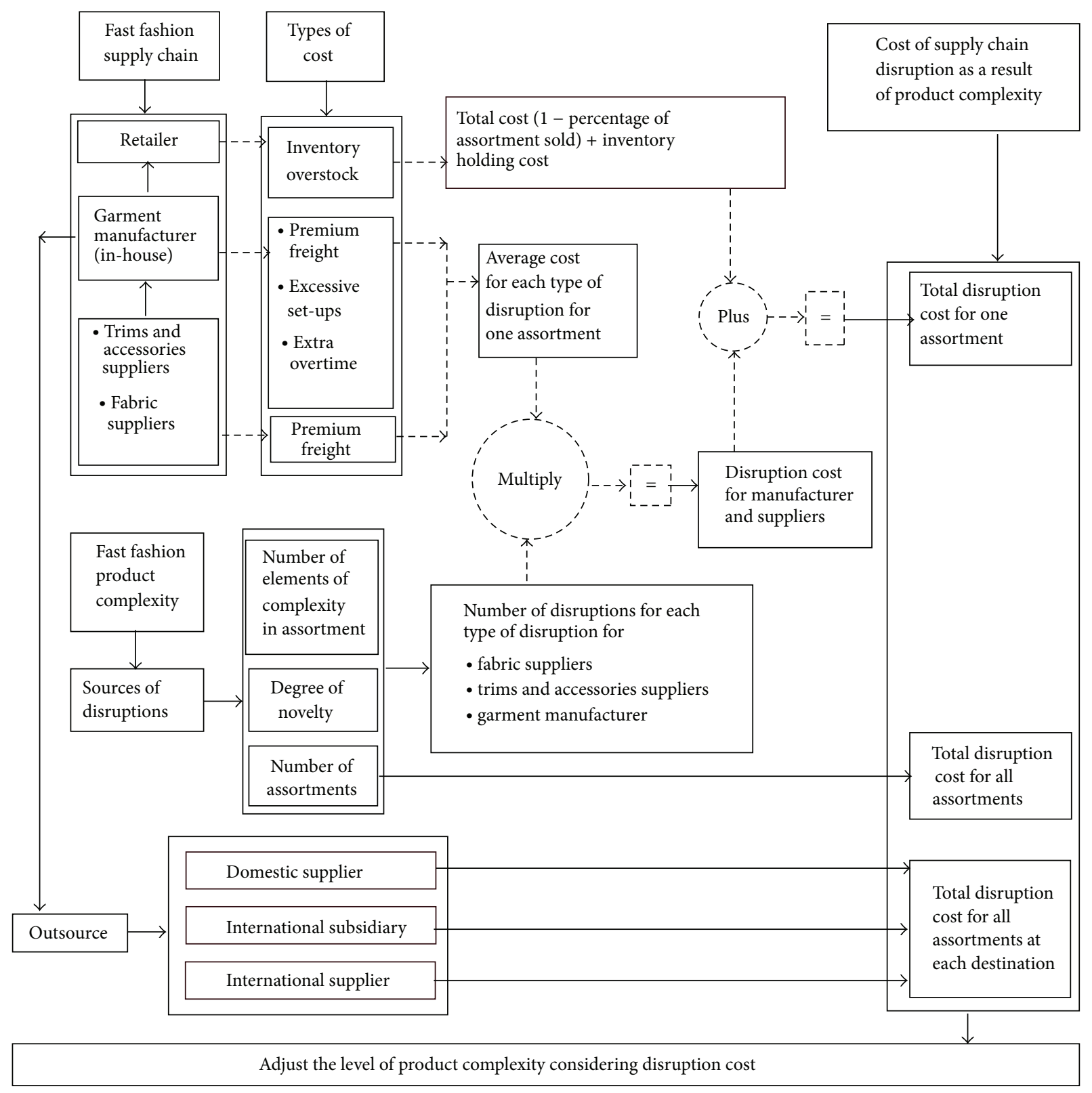

FIGURE 1: Conceptual model to estimate disruption cost as a function of product complexity.

is common in the garment industry to face frequent delays. Suppliers and manufacturers will face premium freight in an effort to ship partial or unexpected deliveries. The same types of premium freight costs can be grouped together and average premium freight cost can be obtained. In this way, managers can develop a database for various cost types to use in the model.

Average cost per one turn/occurrence of premium freight for fabric suppliers at destination $j$ is

$$
\bar{x}_{a, j}=\left(\frac{\sum_{r=1}^{R} \alpha_{r}}{R}\right)_{j} .
$$

Average cost per one occurrence of premium freight for trims and accessories suppliers at destination $j$ is

$$
\bar{x}_{b, j}=\left(\frac{\sum_{k=1}^{K} \beta_{k}}{K}\right)_{j} .
$$

Average cost per one occurrence of premium freight for garment manufacturer at destination $j$ is

$$
\bar{x}_{c 1, j}=\left(\frac{\sum_{p=1}^{P} \gamma_{p}}{P}\right)_{j} \text {. }
$$

Product complexity can cause managers to run production line with extra overtime. Sometimes, fabric suppliers 
or trims and accessories suppliers delay delivery of some types of materials. Sometimes, missing only one part can cause stoppage of the production line or a disturbance of production schedule. Another problem occurs when some new designs are introduced in the sewing line, and operators cannot complete them due to a quality problem or difficulty in performing sewing operations. As a result, the manager is under pressure to run the production line with extra overtime.

Cost of overtime disruption $u$ for garment manufacturer occurring in the past is

$$
\delta_{u}=l(1+\tau) \times \mathfrak{h} \times \mathfrak{R} .
$$

Average cost per one occurrence of overtime for garment manufacturer at destination $j$ is

$$
\bar{x}_{c 2, j}=\left(\frac{\sum_{u=1}^{U} \delta_{u}}{U}\right)_{j}
$$

There are so many styles running in production which results in excessive set-ups. Restoring the production line to working condition can cause the loss of labor hours (e.g., stopping the whole line till removal of some or all items and components, replacing some machines or machine parts, etc.).

Cost of overtime disruption $u$ for garment manufacturer occurring in past is

$$
\varepsilon_{q}=l \times \omega \times \mathfrak{T} .
$$

Average cost per one occurrence of set-up for garment manufacturer at destination $j$ is

$$
\bar{x}_{c 3, j}=\left(\frac{\sum_{q=1}^{Q} \varepsilon_{q}}{Q}\right)_{j}
$$

We assume that the manufacturer must dispatch the whole assortment to the retailer, and unsold inventory becomes obsolete. Due to forecasting errors, imprecise assortment planning, and disruptions occurring at upstream company categories, some of the inventory will be overstocked at retail store resulting in inventory obsolescence and inventory holding cost. Total cost of manufacturing for an assortment is the sum of unit production cost, transportation cost, and transaction cost.

Total cost of manufacturing for assortment $i$ at destination $j$ is

$$
M_{i, j}=\mathbb{N}_{i} \times\left(\frac{l}{a}+\mathbb{t}+\mathbb{Z}\right) .
$$

Inventory holding cost for assortment $i$ due to destination $j$ for retailer is

$$
H_{i, j}=\left(\mathbb{N}_{i} \times \mathfrak{h}\right)\left(1-\varphi_{i, j}\right)
$$

Inventory overstock cost for assortment $i$ due to destination $j$ for retailer is

$$
O_{i, j}=M_{i, j}\left(1-\varphi_{i, j}\right)+H_{i, j}
$$

Total cost of supply chain disruption for $n$ assortments at destination $j$ is

$$
\begin{aligned}
& \sum_{i=1}^{n}\left\{\left(d_{1}\right)_{i, j} \times\left(\bar{x}_{a}\right)_{j}\right\}+\sum_{i=1}^{n}\left\{\left(d_{2}\right)_{i, j} \times\left(\bar{x}_{b}\right)_{j}\right\} \\
& +\sum_{i=1}^{n}\left\{\left(d_{3}\right)_{i, j} \times\left(\bar{x}_{c 1}\right)_{j}\right\}+\sum_{i=1}^{n}\left\{\left(d_{4}\right)_{i, j} \times\left(\bar{x}_{c 2}\right)_{j}\right\} \\
& +\sum_{i=1}^{n}\left\{\left(d_{5}\right)_{i, j} \times\left(\bar{x}_{c 3}\right)_{j}\right\}+\sum_{i=1}^{n}\left\{M_{i, j}\left(1-\varphi_{i, j}\right)+H_{i, j}\right\}, \quad \forall j, \\
& \sum_{i=1}^{n}\left\{\left(d_{1}\right)_{i, j} \times\left(\frac{\sum_{r=1}^{R} \alpha_{r}}{R}\right)_{j}\right\}+\sum_{i=1}^{n}\left\{\left(d_{2}\right)_{i, j} \times\left(\frac{\sum_{k=1}^{K} \beta_{k}}{K}\right)_{j}\right\} \\
& +\sum_{i=1}^{n}\left\{\left(d_{3}\right)_{i, j} \times\left(\frac{\sum_{p=1}^{P} \gamma_{p}}{P}\right)_{j}\right\} \\
& +\sum_{i=1}^{n}\left\{\left(d_{4}\right)_{i, j} \times\left(\frac{\sum_{\mathcal{u}=1}^{U} l(1+\tau) \times \mathfrak{h} \times \mathfrak{R}}{U}\right)_{j}\right\} \\
& +\sum_{i=1}^{n}\left\{\left(d_{5}\right)_{i, j} \times\left(\frac{\sum_{q=1}^{\mathrm{Q}} l \times \omega \times \mathfrak{T}}{Q}\right)_{j}\right\} \\
& +\sum_{i=1}^{n}\left[\left\{\mathbb{N}\left(\frac{l}{a}+\mathbb{t}+\mathbb{Z}\right)\right\}_{i, j}\left(1-\varphi_{i, j}\right)+\left(\mathbb{N}_{i} \mathfrak{h}\right)\left(1-\varphi_{i, j}\right)\right],
\end{aligned}
$$

Disruption factor without impact of assortments can be considered as "predefined disruption factor based on manufacturing destination." Disruption factor variations based on manufacturing destination are due to (i) variations in distance, transportation modes, and border crossings between suppliers, garment manufacturer, and retailer and (ii) different level of experiences and skills for different manufacturers. Disruption factor with impact of assortments can be derived from disruption factor without impact of assortments by incorporating the impact of successive increase of assortments in the supply chain as well as elements of product complexity within each assortment.

Disruption factor with impact of assortments for premium freight disruptions for fabric suppliers at destination $j$ is

$$
\exists 1_{i, j}=\Omega_{1, j}\left\{1+\frac{n\left(E 1_{i}+E 2_{i}+E 3_{i}\right)}{\sum_{i=1}^{n}\left(E 1_{i}+E 2_{i}+E 3_{i}\right)}\right\}, \quad \forall i, j .
$$

Number of premium freight disruptions for fabric suppliers for assortment $i$ at destination $j$ can be expressed as

$$
\left(d_{1}\right)_{i, j}=\exists 1_{i, j} \times f 1_{i}, \quad \forall i, j,
$$

$$
\left(d_{1}\right)_{i, j}=f 1_{i} \Omega_{1, j}\left\{1+\frac{n\left(E 1_{i}+E 2_{i}+E 3_{i}\right)}{\sum_{i=1}^{n}\left(E 1_{i}+E 2_{i}+E 3_{i}\right)}\right\}, \quad \forall i, j,
$$


and, similarly,

$$
\begin{array}{ll}
\left(d_{2}\right)_{i, j}=f 2_{i} \Omega_{2, j}\left\{1+\frac{n\left(E 1_{i}+E 2_{i}+E 3_{i}\right)}{\sum_{i=1}^{n}\left(E 1_{i}+E 2_{i}+E 3_{i}\right)}\right\}, & \forall i, j, \\
\left(d_{3}\right)_{i, j}=f 3_{i} \Omega_{3, j}\left\{1+\frac{n\left(E 1_{i}+E 2_{i}+E 3_{i}\right)}{\sum_{i=1}^{n}\left(E 1_{i}+E 2_{i}+E 3_{i}\right)}\right\}, & \forall i, j, \\
\left(d_{4}\right)_{i, j}=f 4_{i} \Omega_{4, j}\left\{1+\frac{n\left(E 1_{i}+E 2_{i}+E 3_{i}\right)}{\sum_{i=1}^{n}\left(E 1_{i}+E 2_{i}+E 3_{i}\right)}\right\}, & \forall i, j, \\
\left(d_{5}\right)_{i, j}=f 5_{i} \Omega_{5, j}\left\{1+\frac{n\left(E 1_{i}+E 2_{i}+E 3_{i}\right)}{\sum_{i=1}^{n}\left(E 1_{i}+E 2_{i}+E 3_{i}\right)}\right\}, & \forall i, j .
\end{array}
$$

Retailers will face diverse problems as a result of unique nature of product complexity at each production destination, and overstock cost, set-up, and overtime costs will be different due to huge difference of labor cost. Therefore, overall supply chain disruption cost for different assortments at different manufacturing destinations is dissimilar.

\section{Numerical Experiments}

This section performs quantitative experiments to analyze the impact of product complexity on supply chain design. Table 4 summarizes the compact form of data generated for numerical experiments. Let us assume that 10 assortments are running simultaneously in the supply chain required by a retailer. Garment manufacturing is supposed to be kept in home country or in host country. Managers select one low cost developing market (i.e., host country) to outsource the garment manufacturing process. There are four manufacturing options: make in-house in home country, domestic supplier in home country, international subsidiary in host country, and international supplier in host country. We want to check the impact of product complexity on supply chain design in three cases. We generate input data for these three cases based on equations developed in previous sections and solid evidence from the literature $[2,11,13,46-49]$.

4.1. Case A: Suppliers and Retailer Are Situated in Home Country. In this case, sourcing of fabric, trims, and accessories is compulsory from suppliers in home country. Shipping of manufactured product from any global destination is required by a retailer in home country. Managers want to check and compare the impact of product complexity (in the form of disruption cost) at four global destinations. Ultimate purpose is to find the best alternative for supply chain design. By using mathematical model, we estimate the cost of supply chain disruption as a function of product complexity. Figure 2 shows that as the product complexity increases, total cost of supply chain disruption also increases. It is obvious from Figure 3 that successive increases in number of assortments cause the increase in disruption cost. Also the disruption cost fluctuates from assortment to assortment. These effects are due to disruption factor which incorporates the impact of successive increase of assortments in the supply chain as well as elements of product complexity within each

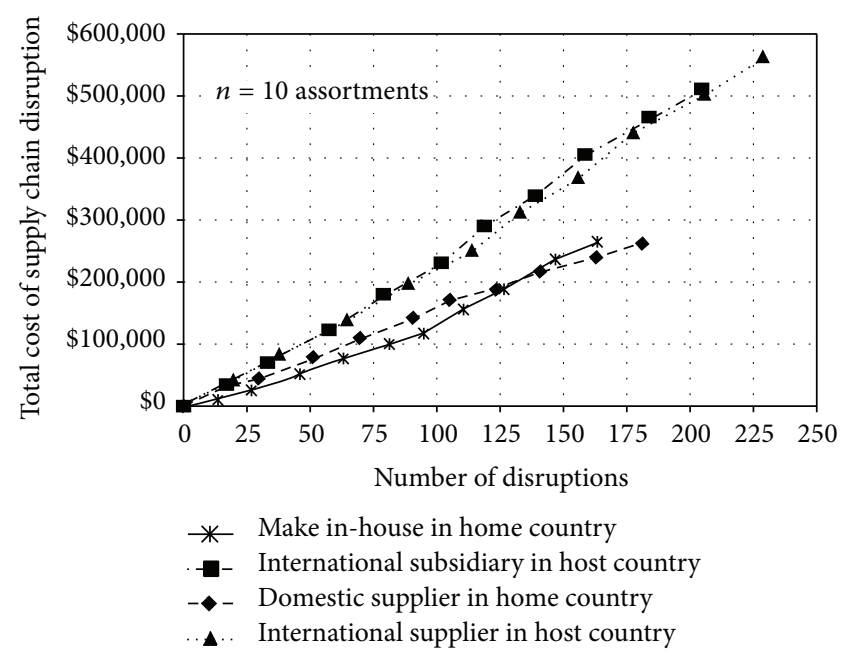

FIgURE 2: Case A: total disruption cost as a function of product complexity.

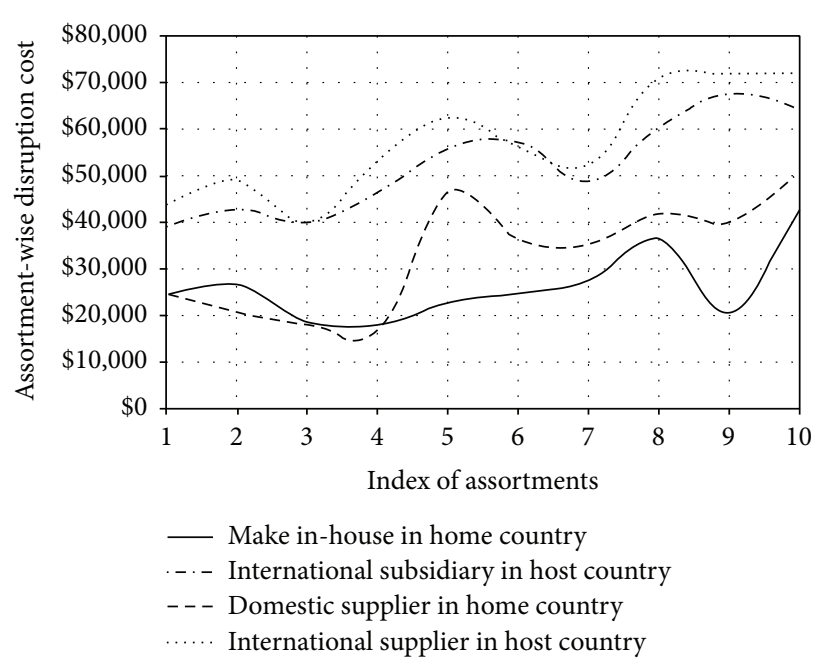

FIgURE 3: Case A: assortment-wise disruption cost as a function of product complexity.

assortment. In the present case, supply chain disruption is clearly high for offshoring and global outsourcing. Therefore, keeping production in-house (i.e., home country) is the best alternative.

4.2. Case B: Suppliers and Retailer Are Situated in Host Country. In this case, sourcing of fabric, trims, and accessories is unavoidable from host country due to some key reasons. The shipping of final product from any global destination is required by a retailer in host country. Figures 4 and 5 show that supply chain disruption is clearly high for the home country. The host country is always feasible for this situation.

4.3. Case C: Suppliers and Retailer Are Situated in any Country Other Than the Home Country and the Host Country. In this case, sourcing is unavoidable from countries other than home country and host country. Shipping of the final product from any manufacturing destination is required by a retailer in 
TABLE 4: Input data for the model (all costs in US \$).

\begin{tabular}{|c|c|c|c|c|c|c|}
\hline \multirow{2}{*}{\multicolumn{3}{|c|}{ Factors }} & \multicolumn{4}{|c|}{ Location of garment manufacturing } \\
\hline & & & Make in-house & $\begin{array}{l}\text { Domestic } \\
\text { supplier }\end{array}$ & $\begin{array}{l}\text { International } \\
\text { subsidiary }\end{array}$ & $\begin{array}{l}\text { International } \\
\text { supplier }\end{array}$ \\
\hline \multicolumn{3}{|c|}{ Hourly compensation or labor cost per hour } & 40 & 40 & 4.28 & 4.28 \\
\hline \multicolumn{3}{|c|}{ Number of hours consumed on one occurrence of set-up } & 1.2 & 1.2 & 1.2 & 1.2 \\
\hline \multicolumn{3}{|c|}{ Number of workers assigned to one occurrence of set-up } & 8 & 8 & 8 & 8 \\
\hline \multicolumn{3}{|l|}{ Overtime allowance per hour } & $50 \%$ & $50 \%$ & $50 \%$ & $50 \%$ \\
\hline \multicolumn{3}{|c|}{ Number of hours consumed per one occurrence of overtime } & 2.5 & 2.5 & 2.5 & 2.5 \\
\hline \multicolumn{3}{|c|}{ Number of workers assigned to one occurrence of overtime } & 12 & 12 & 12 & 12 \\
\hline \multicolumn{3}{|c|}{ Percentage of unit production cost which is comprised of labor cost } & $50 \%$ & $50 \%$ & $25 \%$ & $25 \%$ \\
\hline \multicolumn{3}{|c|}{$\begin{array}{l}\text { Transportation cost for an average garment (\% of unit } \\
\text { production cost) }\end{array}$} & $5 \%$ & $5 \%$ & $20 \%$ & $20 \%$ \\
\hline \multicolumn{3}{|c|}{$\begin{array}{l}\text { Transaction cost for an average garment (\% of unit production } \\
\text { cost) }\end{array}$} & $2 \%$ & $3 \%$ & $10 \%$ & $10 \%$ \\
\hline \multicolumn{3}{|c|}{ Number of items in each assortment } & 2000 & 2000 & 2000 & 2000 \\
\hline \multicolumn{3}{|c|}{ Total cost of manufacturing (Different for each destination) } & Assumed & $\begin{array}{l}10 \% \text { higher than } \\
\text { in-house }\end{array}$ & $\begin{array}{l}50 \% \text { lower than } \\
\text { in-house }\end{array}$ & $\begin{array}{l}10 \% \text { higher than } \\
\text { subsidiary }\end{array}$ \\
\hline \multicolumn{3}{|l|}{ Percentage of assortment sold } & $83 \%-100 \%$ & $83 \%-100 \%$ & $83 \%-100 \%$ & $83 \%-100 \%$ \\
\hline \multicolumn{3}{|c|}{ Inventory holding cost for obsolete stock } & \multicolumn{4}{|c|}{$12 \%$ of obsolete stock } \\
\hline \multicolumn{7}{|l|}{ Case A } \\
\hline \multicolumn{3}{|c|}{$\begin{array}{l}\text { Premium freight disruption cost from (i) Fabric suppliers to } \\
\text { garment manufacturer; (ii) garment manufacturer to retailer }\end{array}$} & 3000 & 3000 & 12500 & 12500 \\
\hline \multicolumn{3}{|c|}{$\begin{array}{l}\text { Premium freight disruption cost from trims and accessories } \\
\text { suppliers to garment manufacturer }\end{array}$} & 200 & 200 & 250 & 250 \\
\hline \multicolumn{7}{|l|}{ Case B } \\
\hline \multicolumn{3}{|c|}{$\begin{array}{l}\text { Premium freight disruption cost from (i) fabric suppliers to } \\
\text { garment manufacturer; (ii) garment manufacturer to retailer }\end{array}$} & 12500 & 12500 & 3000 & 3000 \\
\hline \multicolumn{3}{|c|}{$\begin{array}{l}\text { Premium freight disruption cost from trims and accessories } \\
\text { suppliers to garment manufacturer }\end{array}$} & 250 & 250 & 200 & 200 \\
\hline \multicolumn{7}{|c|}{ Case $C$} \\
\hline \multicolumn{3}{|c|}{$\begin{array}{l}\text { Premium freight disruption cost from (i) fabric suppliers to } \\
\text { garment manufacturer; (ii) garment manufacturer to retailer }\end{array}$} & 12500 & 12500 & 12500 & 12500 \\
\hline $\begin{array}{l}\text { Premium freight disruption cost } \\
\text { suppliers to garment manufactu }\end{array}$ & rom trims an & accessories & 250 & 250 & 250 & 250 \\
\hline Company category & $\begin{array}{l}\text { Elements of } \\
\text { complexity }\end{array}$ & Type of cost & Predefined & disruption factor & vithout impact of & assortments \\
\hline Case A & & & & & & \\
\hline Fabric suppliers & $30-48$ & Premium freight & 0.50 & 0.55 & 0.63 & 0.70 \\
\hline Trims and accessories suppliers & $15-54$ & Premium freight & 0.50 & 0.55 & 0.63 & 0.70 \\
\hline & & Premium freight & 0.25 & 0.28 & 0.31 & 0.35 \\
\hline Garment manufacturing & $50-84$ & Overtime & 0.25 & 0.28 & 0.31 & 0.35 \\
\hline & & Set-up & 0.25 & 0.28 & 0.31 & 0.35 \\
\hline Case B & & & & & & \\
\hline Fabric suppliers & $30-48$ & Premium freight & 0.63 & 0.70 & 0.50 & 0.55 \\
\hline Trims and accessories suppliers & $15-54$ & Premium freight & 0.63 & 0.70 & 0.50 & 0.55 \\
\hline & & Premium freight & 0.31 & 0.35 & 0.25 & 0.28 \\
\hline Garment manufacturing & $50-84$ & Overtime & 0.31 & 0.35 & 0.25 & 0.28 \\
\hline & & Set-up & 0.31 & 0.35 & 0.25 & 0.28 \\
\hline Case $C$ & & & & & & \\
\hline Fabric suppliers & $30-48$ & Premium freight & 0.63 & 0.70 & 0.63 & 0.70 \\
\hline Trims and accessories suppliers & $15-54$ & Premium freight & 0.63 & 0.70 & 0.63 & 0.70 \\
\hline & & Premium freight & 0.31 & 0.35 & 0.31 & 0.35 \\
\hline Garment manufacturing & $50-84$ & Overtime & 0.31 & 0.35 & 0.31 & 0.35 \\
\hline & & Set-up & 0.31 & 0.35 & 0.31 & 0.35 \\
\hline
\end{tabular}




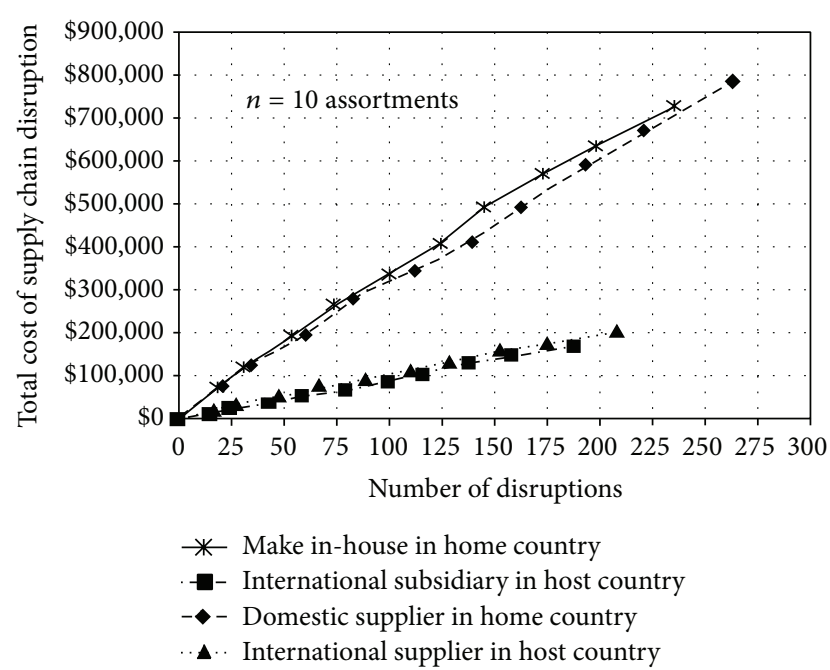

Figure 4: Case B: total disruption cost as a function of product complexity.

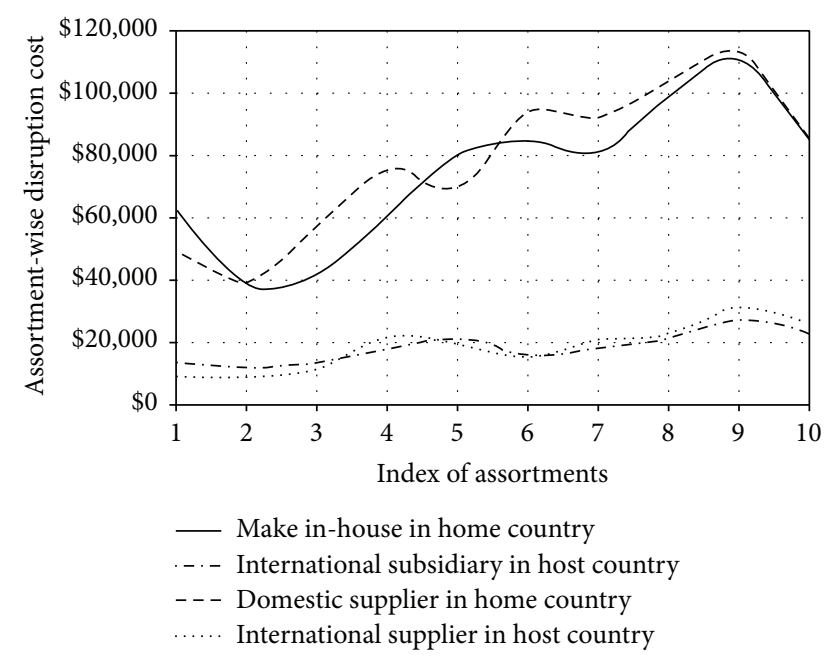

FIGURE 5: Case B: assortment-wise disruption cost as a function of product complexity.

a country other than the home country and the host country. Looking at the overall situation of the present case, the supply chain disruption cost is much higher for the home country as well as host country (Figures 6 and 7). One solution is to choose a third country for manufacturing (new host country) other than home country and existing host country in such a way that both suppliers and retailer or one of them is located in the new host country. We assumed that manufacturing must be performed in home country or existing host country. In this situation, outsourcing to host country looks more attractive due to lower disruption cost.

Case A clearly discourages outsourcing. Case B and Case $\mathrm{C}$ are in favor of outsourcing. A key reason for the inclination of fast fashion companies towards outsourcing and offshoring is that excessive disruption cost is offset by the lower unit production cost at the global low cost destinations. This paper estimated the impact of product complexity for three cases.

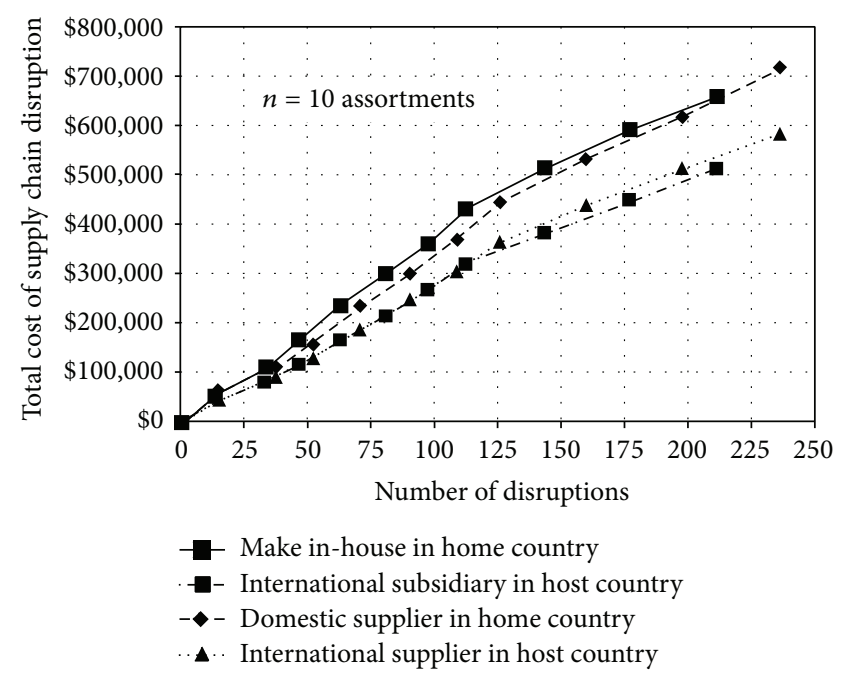

Figure 6: Case C: total disruption cost as a function of product complexity.

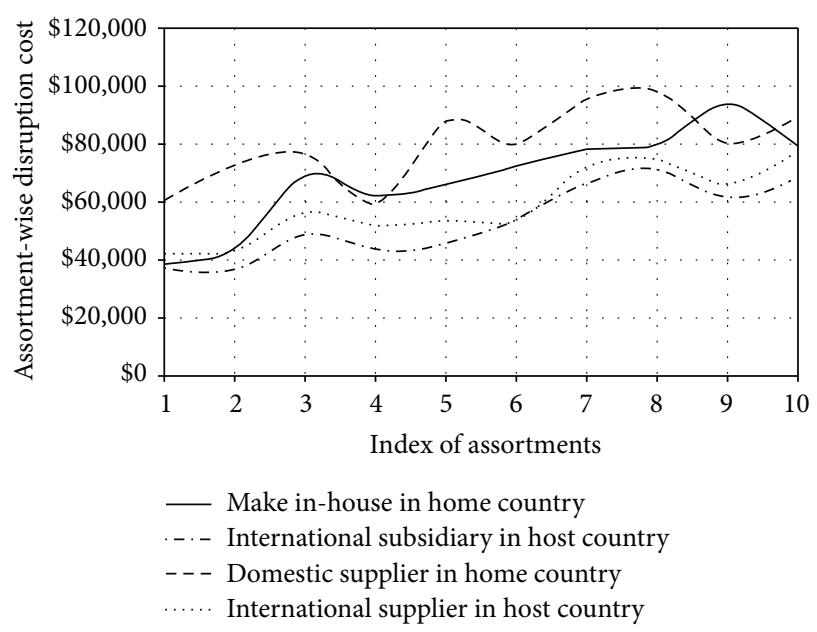

Figure 7: Case C: assortment-wise disruption cost as a function of product complexity.

There are various possibilities of supply chain design which can be analyzed by using the model proposed in this paper.

\section{Adjusting the Level of Product Complexity across the Supply Chain}

The key objective of this section is to generalize the problem of product complexity to implement the research result for any size of problem. Our focus is the product complexity related to elements of product complexity, degree of novelty in an assortment, and number of assortments running in supply chain. This analysis is specific to fast fashion supply chain but can be adapted to other supply chains after associated adjustments.

Let

$v$ : index of company categories in supply chain, $v=$ $1,2,3, \ldots, V$, 
$z$ : index of types of cost of product complexity/novelty, $z=1,2,3, \ldots, Z$,

$B_{i, j}$ : budget fixed for cost of product complexity/novelty in supply chain,

$E_{i, v}$ : existing number of elements of product complexity for company category $v$ in assortment $i$,

$E_{i, j, v}^{0}:$ required number of elements of product complexity for company category $v$ in assortment $i$ at destination $j$,

$f_{i, j, z}$ : existing frequency of occurrence of type of cost $z$ for assortment $i$ at destination $j$,

$f_{i, j, z}^{0}$ : required frequency of occurrence of type of cost $z$ for assortment $i$ at destination $j$,

$b_{i, v}$ : existing number of novel elements of product complexity for company category $v$ in assortment $i$,

$b_{i, j, v}^{0}$ : required number of novel elements of product complexity for company category $v$ in assortment $i$ at destination $j$,

$\exists_{i, j, z}$ : disruption factor with impact of assortments for type of cost $z$ for assortment $i$ at destination $j$,

$\Omega_{z, j}$ : disruption factor without impact of assortments for type of cost $z$ at destination $j$,

$\bar{x}_{z, j}$ : average cost per one occurrence/turn of type of cost $z$ at destination $j$,

$Y_{i, j}$ : binary variable for selection of manufacturing destination $j$ for assortment $i$,

$d_{i, j, z}$ : number of disruptions for type of cost $z$ for assortment $i$ at destination $j$,

$g_{i, j, z}$ : average number of acceptable elements per one occurrence of type of cost $z$ in assortment $i$ at destination $j$.

\subsection{Managing the Number of Elements of Product Complexity}

(i) Identify key types of cost of product complexity (i.e., $Z$ ) across the supply chain, $z=1,2,3 \ldots Z$.

(ii) Allocate acceptable budget $B_{i, j}$ to total cost of product complexity across the supply chain.

(iii) Calculate the weight of the budget to be allocated to the individual cost of product complexity as "ratio of the number of elements of product complexity in company category $v$ to the product of $Z$ number of costs of product complexity and total number of elements in all (i.e., $V$ ) company categories."

(iv) Calculate the fraction of budget to be allocated to individual cost of complexity as "product of acceptable budget $B_{i, j}$ and weight of budget to be allocated to individual cost of product complexity."

(v) Calculate acceptable frequency of occurrence $\left(f_{i, j, z}^{0}\right)$ as "ratio of fraction of budget to be allocated to individual cost of complexity to average cost per one occurrence/turn of type of cost $z$ " as follows:

$$
f_{i, j, z}^{0}=\frac{B_{i, j}\left\{E_{i, v} /\left(Z\left(\sum_{v=1}^{V} E_{i, v}\right)\right)\right\}}{\bar{x}_{j, z}}, \quad \forall i, j, z .
$$

(i) Calculate acceptable number of elements of product complexity as follows:

$$
E_{i, j, z}^{0}=\frac{B_{i, j}\left(E_{i, v}\right)^{2}}{\bar{x}_{j, z} f_{i, j, z} Z\left(\sum_{v=1}^{V} E_{i, v}\right)}, \quad \forall i, j, v .
$$

(ii) Calculate acceptable number of elements of product complexity considering expected disruptions as follows:

$$
E_{i, j, v}^{0}=\frac{B_{i, j}\left(E_{i, v}\right)^{2}}{\bar{x}_{j, z} Z\left(f_{i, j, z}+d_{i, j, z}\right)\left(\sum_{v=1}^{V} E_{i, v}\right)}, \quad \forall i, j, v .
$$

If

$$
\begin{gathered}
d_{i, z, j}=\exists_{i, j, z} \times f_{z, i, j}, \quad \forall i, j, z, \\
E_{i, j, v}^{0}=\frac{B_{i, j}\left(E_{i, v}\right)^{2}}{\bar{x}_{j, z} f_{i, j, z} Z\left\{1+\exists_{i, j, z}\right\}\left(\sum_{v=1}^{V} E_{i, v}\right)}, \quad \forall i, j, v .
\end{gathered}
$$

Average number of acceptable elements per turn of cost of product complexity is as follows:

$$
g_{i, j, z}=\frac{E_{i, j, v}^{0}}{f_{i, j, z}^{0}}, \quad \forall i, j, z .
$$

Average number of acceptable elements per turn of cost of product complexity considering disruptions should be as follows:

$$
g_{i, j, z}=\frac{E_{i, j, v}^{0}}{f_{i, j, z}^{0}-d_{i, j, z}}, \quad \forall i, j, z .
$$

This shows that disruption can be adjusted by increasing the elements per occurrence/turn of cost of product complexity.

\subsection{Managing the Degree of Product Novelty}

(i) Identify key types of cost of product novelty (i.e., $Z$ ) across the supply chain $z=1,2,3 \ldots Z$.

(ii) Allocate acceptable budget $B_{i, j}$ to total cost of product novelty across the supply chain.

(iii) Calculate degree of novelty for individual company category as ratio of number of novel elements $\left(b_{i, v}\right)$ of product complexity in company category $v$ to total number of elements of complexity $\left(E_{i, v}\right)$ in company category $v$.

(iv) Calculate degree of novelty for all (i.e., $V$ ) company categories as "sum of degree of product novelty of all company categories." 
(v) Calculate weight of budget to be allocated to individual cost of product novelty as "ratio of the product novelty in company category $v$ to the product of $Z$ number of costs of product novelty and degree of novelty for all (i.e., $V$ ) company categories."

(vi) Calculate fraction of budget to be allocated to individual cost of product novelty as "product of acceptable budget $B_{i, j}$ and weight of budget to be allocated to individual cost of product novelty."

(vii) Calculate acceptable frequency of occurrence $\left(f_{i, j, z}^{0}\right)$ as "ratio of fraction of budget to be allocated to individual cost of product novelty to average cost per one occurrence/turn of type of cost $z$ " as follows:

$$
f_{i, j, z}^{0}=\frac{B_{i, j}\left\{\left(b_{i, v} / E_{i, v}\right) /\left(Z\left(\sum_{v=1}^{V}\left(b_{i, v} / E_{i, v}\right)\right)\right)\right\}}{\bar{x}_{z, j}}, \quad \forall i, j, z .
$$

Calculate the acceptable number of novel elements of product complexity as follows:

$$
b_{i, j, v}^{0}=\frac{B_{i, j}\left(b_{i, v} / E_{i, v}\right)^{2}}{\bar{x}_{z, j} f_{i, j, z} Z\left(\sum_{v=1}^{V}\left(b_{i, v} / E_{i, v}\right)\right)}, \quad \forall i, j, v .
$$

Calculate the acceptable number of novel elements of product novelty considering expected disruptions as follows:

$$
\begin{aligned}
& b_{i, j, v}^{0}=\frac{B_{i, j}\left(b_{i, v} / E_{i, v}\right)^{2}}{\bar{x}_{z, j} Z\left(f_{i, j, z}+d_{i, j, z}\right)\left(\sum_{v=1}^{V}\left(b_{i, v} / E_{i, v}\right)\right)}, \quad \forall i, j, v, \\
& b_{i, j, v}^{0}=\frac{B_{i, j}\left(b_{i, v} / E_{i, v}\right)^{2}}{\bar{x}_{z, j} f_{i, j, z} Z\left\{1+\exists_{i, j, z}\right\}\left(\sum_{v=1}^{V}\left(b_{i, v} / E_{i, v}\right)\right)}, \quad \forall i, j, v .
\end{aligned}
$$

Once the acceptable number of elements and frequency of occurrence of cost of product complexity/product novelty are determined, we can compare them with actual product complexity/novelty. This approach will help us to (i) highlight the areas of supply chain influenced by excessive cost of product complexity; (ii) detect and eliminate bottlenecks in supply chain; and (iii) keep full control on our products and supply chains.

5.3. Managing the Number of Assortments. Calculate the disruption factor considering total number of assortments and their individual complexity as follows:

$$
\exists_{i, j, z}=\Omega_{z, j}\left\{1+\frac{n\left(\sum_{v=1}^{V} E_{i, v}\right)}{\sum_{i=1}^{n} \sum_{v=1}^{V} E_{i, v}}\right\}, \quad \forall i, j, z .
$$

Calculate the number of expected disruptions as follows:

$$
d_{i, j, z}=f_{i, j, z} \Omega_{z, j}\left\{1+\frac{n\left(\sum_{v=1}^{V} E_{i, v}\right)}{\sum_{i=1}^{n} \sum_{v=1}^{V} E_{i, v}}\right\}, \quad \forall i, j, z .
$$

Assign the number of assortments to the potential manufacturing destinations as follows:

$$
\begin{gathered}
\sum_{j=1}^{m} \sum_{i=1}^{n}\left[\sum_{z=1}^{Z}\left(d_{i, j, z}\right) \bar{x}_{z, j}+\left(1-\varphi_{i, j}\right)\left(M_{i, j}+\mathbb{N}_{i} \mathfrak{h}\right)\right] \times Y_{i, j}, \\
\sum_{j=1}^{m} \sum_{i=1}^{n}\left[\sum_{z=1}^{Z}\left(\exists_{i, j, z} \times f_{i, j, z}\right) \bar{x}_{z, j}+\left(1-\varphi_{i, j}\right)\left(M_{i, j}+\mathbb{N}_{i} \mathfrak{h}\right)\right] \\
\times Y_{i, j}, \\
\sum_{j=1}^{m} \sum_{i=1}^{n}\left[\sum_{z=1}^{Z}\left\{f_{i, j, z} \Omega_{z, j}\left(1+\frac{n\left(\sum_{v=1}^{V} E_{i, v}\right)}{\sum_{i=1}^{n} \sum_{v=1}^{V} E_{i, v}}\right)\right\} \bar{x}_{z, j}\right. \\
\left.+\left(1-\varphi_{i, j}\right)\left(M_{i, j}+\mathbb{N}_{i} \mathfrak{h}\right)\right] \times Y_{i, j} .
\end{gathered}
$$

\section{Insights for Practitioners}

Focus of this section is to propose several possible strategies based on our research results to manage the impact of product complexity for effective supply chain design.

6.1. Managing the Number of Elements of Product Complexity at Product Design and Assortment Planning Stage. At the weaving/knitting stage, the maximum items must be planned to contain common fabric structures to be made with common manufacturing procedures. At the processing stage, fast fashion companies should decrease the number of colors to decrease the frequent set-ups. Hundreds of trims and accessories are required within the specific limit of time. In order to decrease the risk of missing a trim or accessory, companies should consider the decrease in the number and variety of trims and accessories. Common fabrics, trims, or accessories can be used in a different ways to produce different styles. In the cutting stage, fabric cut parts can be decreased using effective pattern making techniques. Maximum variety of designs should be planned by standardization of the possible sewing operation types within an assortment.

6.2. Managing the Degree of Novelty/Newness at Product Design and Assortment Planning Stage. Product novelty is associated with the difficulty of producing innovative designs by using the same labor force and technology. We can simplify the designs fabric, trim, or accessory to match the corresponding supply chain processes. Fast fashion companies should develop the recipes of the innovative colors in collaboration with fabric suppliers. New cut parts and sewing operations in a garment should be developed by keeping in view the compatibility of manufacturing destination.

6.3. Managing the Number of Assortments by Right Allocation of Assortments to Global Destinations. Usually, the companies are involved in simultaneous production and distribution of several assortments. While making the manufacturing decisions, the assortments with a high degree of commonality 
must be produced by single destination when possible. For example, the assortments with (greater degree of) common bill of materials (BOM) can be assigned to the same garment manufacturer. When making the outsourcing decisions, companies should assign the assortments based on similarities in assortments, experiences of destination manufacturers, deadlines, and innovation adoption capabilities.

6.4. Decentralization of Distribution Centers. A well-established fast fashion business may have thousands of retail locations all around the world (H\&M has 2653 stores in 54 countries and Zara has 1972 stores in 89 countries). Only one centralized distribution system for all retail stores can increase the supply chain disruption cost to an undesirable level, resulting in long term failure of supply chain design and loss of competiveness. It seems more practical to establish number of distribution centers based on geographical location of retailers.

6.5. Alignment of Consumer Preferences with Product Design and Assortment Planning. In fast fashion stores, forecasting inaccuracies combined with disruptions caused by upstream echelons will always disturb the retailer's profit. Obsolete inventory is not only due to late arrival of assortments in the store, but also due to the fact that consumer did not find an attractive product and simply left the store. A key approach to manage this issue is to "incorporate the capabilities of the upstream supply chain as well as consumer preferences into the retail assortments simultaneously."

6.6. Strategic Outsourcing Decisions. Strategic outsourcing decisions will increase the international experiences of the fast fashion companies, which will be beneficial to deal with disruptions and future challenges in supply chains. In the fast fashion context, markdowns have more influence on the retailer's profit than stock-outs. Outsourcing can help in offsetting markdowns and obsolete inventories, providing capacity flexibility required for globally dispersed chain of retail stores, increase in probability of consumer-based allocations of assortments, high global market penetration, and long term competitiveness.

6.7. Trade-Off between Outsourcing and Ethical Responsibility. Two strategies can be adopted to optimize the trade-off between outsourcing and ethical responsibility. First strategy is to identify the assortments which have a higher degree of supplier availability in the home country or near the home country and then meet the demand for retailers in home country by (i) establishing maximum manufacturing facilities in home country and (ii) utilizing domestic outsourcing if required. Second strategy is to identify the assortments which have a higher degree of supplier availability in another country or near that country and then meet the demand for retailers in that country by (i) assigning maximum production to suppliers in that country and (ii) establishing manufacturing facilities in that country if required (e.g., strategic partnership seems more practical than establishing a fully owned manufacturing subsidiary in the international markets).

\section{Conclusions and Future Work}

This paper highlights the importance of product complexity in the fast fashion supply chain and suggests that we should consider product complexity in addition to quick response in order to address the problem of supply chain complexity. This paper proposed a model to estimate the cost of supply chain disruption as a function of product complexity in the fast fashion supply chain. Findings suggest that key drivers of product complexity in the fast fashion industry include the number of elements of product complexity in an assortment, degree of novelty in an assortment, and number of assortments running in supply chain. This complexity results in many types of cost of product complexity/disruption at different company categories of supply chain across the globe. An estimation of supply chain disruption cost will help us to increase visibility and eliminate the bottlenecks in supply chain, and it allows us to design various possible strategies to prevent/mitigate the impact of product complexity. The results show that the increase in globalization of business will always accelerate the outsourcing and offshoring strategies. Unfortunately, unplanned outsourcing will strengthen the roots of product complexity resulting in excessive cost of supply chain disruption. Numerical experiments show that increased distance between suppliers, manufacturers, and retailers will increase the risk and cost of supply chain disruption. Effective supply chain design will always minimize the distance between different company categories of supply chain in order to prevent strategic failure of business. The level of product complexity is required to be determined and needs to be adjusted and managed in case of excessive disruption. The following are some directions for future research:

(i) a model of product complexity to estimate disruption risk as a function of lead time of manufacturer from suppliers and retailers (e.g., each element of complexity in an assortment has its own probability of disruption and lead time);

(ii) more in-depth studies to analyze the impact of product complexity across the supply chain; for example, what is the impact of an uneven number of elements of product complexity and their managing difficulty within each turn of cost of product complexity (e.g., each turn will result in different cost of product complexity);

(iii) efficient methods to determine the level of product complexity and to adjust in case of disruptions;

(iv) an empirical study to elaborate factors identified in this paper;

(v) empirical studies to find interaction between rate of innovations and adoption of global destinations;

(vi) what is the impact of increased product complexity, if materials from suppliers need reinspection/reworking before manufacturing or manufactured products at retailer's warehouse need reinspection/reworking before selling? 
(vii) future studies should consider other supply chains with different nature of products and disruption cost (e.g., automotive, personal computer, chemical, electronics, food, pharmaceutics, etc.).

\section{Conflict of Interests}

This paper includes the names of some fast fashion companies. They are well-known examples to illustrate the realworld significance of the study. The authors declare that there is no conflict of interests regarding the publication of this paper.

\section{Acknowledgments}

This research was supported by Basic Science Research Program through the National Research Foundation of Korea (NRF) funded by the Ministry of Education, Science and Technology (2012R1A1B3000631).

\section{References}

[1] H. J. Hwang and J. Seruga, "An intelligent supply chain management system to enhance collaboration in textile industry," International Journal of $u$ - and e-Service, Science and Technology, vol. 4, pp. 47-62, 2011.

[2] S. Sardar and Y. H. Lee, "Analysis of outsourcing strategies for cost and capacity flexibility in textile supply chain management," in Proceedings of the 17th International Conference on Industrial Engineering Theory, Applications and Practice, Busan, Republic of Korea, October 2013.

[3] C. Chandra and S. Kumar, "An application of a system analysis methodology to manage logistics in a textile supply chain," Supply Chain Management, vol. 5, no. 5, pp. 234-245, 2000.

[4] A. Rajput and A. H. A. Bakar, "A recapitulation of supply chain management (SCM) in conjunction with textile industry," International Journal of Information, Business and Management, vol. 3, no. 1, pp. 39-54, 2011.

[5] J. Su and V. B. Gargeya, "An empirical examination of global supply chain management practices in US textile and apparel industry," Journal of System and Management Sciences, vol. 1, no. 1, pp. 11-20, 2011.

[6] H. Al-Zubaidi and D. Tyler, "A simulation model of quick response replenishment of seasonal clothing," International Journal of Retail \& Distribution Management, vol. 32, no. 6, pp. 320-327, 2004.

[7] G. Li, Y. Kang, M. Liu, and Z. Wang, "Optimal inventory policy under permissible payment delay in fashion supply chains," Mathematical Problems in Engineering, vol. 2014, Article ID 327131, 9 pages, 2014.

[8] W. D. Cooper, "A fresh look at the U.S./Chinese textile and apparel supply chain question," Journal of Textile and Apparel, Technology and Management, vol. 8, no. 2, pp. 1-16, 2013.

[9] L. de Boer, J. Gaytan, and P. Arroyo, "A satisficing model of outsourcing," Supply Chain Management, vol. 11, no. 5, pp. 444455, 2006.

[10] S. Marttonen and T. Karri, "A Conceptual model for assessing profitability of a maintenance outsourcing decision," in Proceedings of the 17th International Working Seminar on Production Economics, Innsbruck, Austria, 2012.
[11] S. Sardar and Y. H. Lee, "Recent researches and future research directions in textile supply chain management," UTCC International Journal of Business and Economics, vol. 4, no. 2, pp. 75$120,2012$.

[12] L. M. Ellram, W. L. Tate, and K. J. Petersen, "Offshoring and reshoring: an update on the manufacturing location decision," Journal of Supply Chain Management, vol. 49, no. 2, pp. 14-22, 2013.

[13] T. M. Choi, Fast Fashion Systems: Theories and Applications, CRC Press, New York, NY, USA, 2013.

[14] L. Zeltzer, V. Limère, H. Van Landeghem, E. Aghezzaf, and J. Stahre, "Measuring complexity in mixed-model assembly workstations," International Journal of Production Research, vol. 51, no. 15, pp. 4630-4643, 2013.

[15] C. L. Hansen, N. H. Mortensen, L. Hvam, and U. Harlou, "Calculation of complexity costs-an approach for rationalizing a product program," in Proceedings of NordDesign, Aalborg, Denmark, August 2012.

[16] S. Novak and S. D. Eppinger, "Sourcing by design: product complexity and the supply chain," Management Science, vol. 47, no. 1, pp. 189-204, 2002.

[17] F. Nordin, I. Lindahl, and S. Brege, "The applicability of integrated solutions offerings: differential effects of product complexity," Journal of Relationship Marketing, vol. 12, no. 1, pp. 59-78, 2013.

[18] R. R. Inman and D. E. Blumenfeld, "Product complexity and supply chain design," International Journal of Production Research, vol. 57, no. 7, pp. 1956-1969, 2014.

[19] N. Orfi, J. Terpenny, and A. Sahin-Sariisik, "Harnessing product complexity: Step lestablishing product complexity dimensions and indicators," Engineering Economist, vol. 56, no. 1, pp. 59-79, 2011.

[20] A. Hashemi, T. Butcher, and P. Chhetri, "A modeling framework for the analysis of supply chain complexity using product design and demand characteristics," International Journal of Engineering, Science and Technology, vol. 5, no. 2, pp. 150-164, 2013.

[21] O. Khan, M. Christopher, and B. Burnes, "The impact of product design on supply chain risk: a case study," International Journal of Physical Distribution and Logistics Management, vol. 38, no. 5, pp. 412-432, 2008.

[22] J. Li, T. M. Choi, and T. E. Cheng, "Mean-variance analysis of two-echelon fast fashion supply chains with returns policy," IEEE Transactions on Systems, Man and Cybernetics-Systems, vol. 44, no. 4, pp. 422-434, 2014.

[23] G. P. Cachon and R. Swinney, "The value of fast fashion: quick response, enhanced design, and strategic consumer behavior," Management Science, vol. 57, no. 4, pp. 778-795, 2011.

[24] D. Berkowitz, J. Moenius, and K. Pistor, "Trade, law, and product complexity," Review of Economics and Statistics, vol. 88, no. 2, pp. 363-373, 2006.

[25] H. Sun, Manufacturing system and supply chain analyses related to product complexity and sequenced parts delivery [Ph.D. dissertation], University of Tennessee, Knoxville, Tenn, USA, 2005.

[26] M. Yu, G. Ye, and B. Qu, "Trade liberalisation, product complexity and productivity improvement: Evidence from chinese firms," World Economy, vol. 36, no. 7, pp. 912-934, 2013.

[27] J. B. Nielsen and L. Hvam, "Product complexity impact on quality and delivery performance," in Proceedings of the World Conference on Mass Customization, Personalization, and CoCreation, San Francisco, Calif, USA, 2011. 
[28] P. C. Oprime, M. O. A. Gonzalez, and J. C. Toledo, "Analysis of the relationship amongst production efficiency, product complexity and target market," in Proceedings of the 19th International Conference on Production Research, Valparaiso, Chile, July-August 2007.

[29] N. A. Hunter and P. Valentino, "Quick response-ten years later," International Journal of Clothing Science and Technology, vol. 7, no. 4, pp. 30-40, 1995.

[30] C. Lin and C. H. Twua, "Fuzzy MCDM for evaluating fashion trend alternatives," International Journal of Clothing Science and Technology, vol. 24, no. 2, pp. 141-153, 2012.

[31] B. Choudhury and T. Holmgren, Supply chain agility towards global outsourcing within fast fashion industry, a case study at Gina tricot [Doctoral dissertation], Jonkoping University, 2011.

[32] S. Costantini, G. de Gasperis, A. Provetti, and P. Tsintza, "A heuristic approach to proposal-based negotiation: with applications in fashion supply chain management," Mathematical Problems in Engineering, vol. 2013, Article ID 896312, 15 pages, 2013.

[33] Z.-H. Hu, Y. Zhao, and T.-M. Choi, "Vehicle routing problem for fashion supply chains with cross-docking," Mathematical Problems in Engineering, vol. 2013, Article ID 362980, 10 pages, 2013.

[34] Y. Yu and V. Lindsay, “Operational effects and firms' responses: Perspectives of New Zealand apparel firms on international outsourcing," International Journal of Logistics Management, vol. 22, no. 3, pp. 306-323, 2011.

[35] A. Größler, B. T. Laugen, R. Arkader, and A. Fleury, "Differences in outsourcing strategies between firms in emerging and in developed markets," International Journal of Operations and Production Management, vol. 33, no. 3, pp. 296-321, 2013.

[36] S. Guercini and A. Runfola, "Sourcing strategies in clothing retail firms: product complexity versus overseas supply chain," Journal of Customer Behaviour, vol. 3, no. 3, pp. 305-334, 2004.

[37] O. Khan, M. Christopher, and A. Creazza, "Aligning product design with the supply chain: a case study," Supply Chain Management, vol. 17, no. 3, pp. 323-336, 2012.

[38] M. Yu, R. Yang, and L. Ma, "The quota-based compensation plan in fashion retailing industry under asymmetric information," Mathematical Problems in Engineering, vol. 2014, Article ID 263419, 11 pages, 2014.

[39] C. S. Tang, "Robust strategies for mitigating supply chain disruptions," International Journal of Logistics: Research and Applications, vol. 9, no. 1, pp. 33-45, 2006.

[40] R. A. Kelley, Inventory redistribution optimization in the fast fashion industry [Doctoral dissertation], Massachusetts Institute of Technology, 2013.

[41] T. M. Choi, C. L. Hui, N. Liu, S. F. Ng, and Y. Yu, "Fast fashion sales forecasting with limited data and time," Decision Support Systems, vol. 59, pp. 84-92, 2014.

[42] T.-M. Choi, "Local sourcing and fashion quick response system: the impacts of carbon footprint tax," Transportation Research E: Logistics and Transportation Review, vol. 55, pp. 43-54, 2013.

[43] M. K. Bhardwaj, Glossary of Purchasing \& Supply Chain Management, Excel Books, New Delhi, India, 2009.

[44] K. Ferdows, M. A. Lewis, and J. A. D. Machuca, "Rapid-fire fulfillment," Harvard Business Review, vol. 82, no. 11, pp. 104$117,2004$.

[45] N. Tokatli, "Global sourcing: insights from the global clothing industry: the case of Zara, a fast fashion retailer," Journal of Economic Geography, vol. 8, no. 1, pp. 21-38, 2008.
[46] E. Ashley, Outsourcing for Dummies: Determine the Value of Outsourcing for Any Business Process, Wiley, Indianapolis, Ind, USA, 2008.

[47] V. R. Kothari and J. Sanket, "Fashion merchandising: garment costing," 2013, http://www.textiletoday.com/.

[48] The World Bank, Air Freight: A Market Study with Implications for Landlocked Countries, Transport Papers, Transport Sector Board, Washington, DC, USA, 2009, http://www.worldbank .org/.

[49] USAID, "Cost Competitiveness of Pakistan's Textiles and Apparel Industry, 2009," http://egateg.usaid.gov/. 


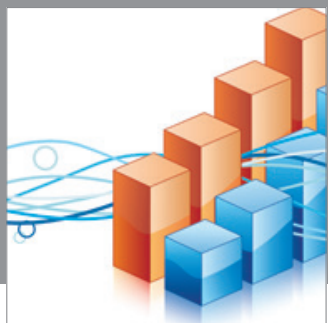

Advances in

Operations Research

mansans

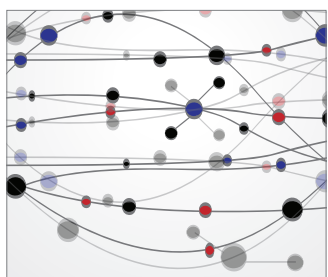

The Scientific World Journal
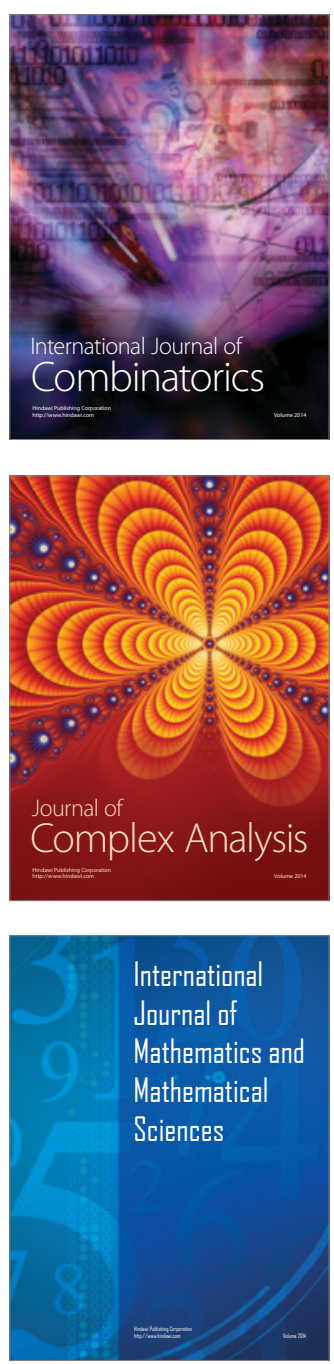
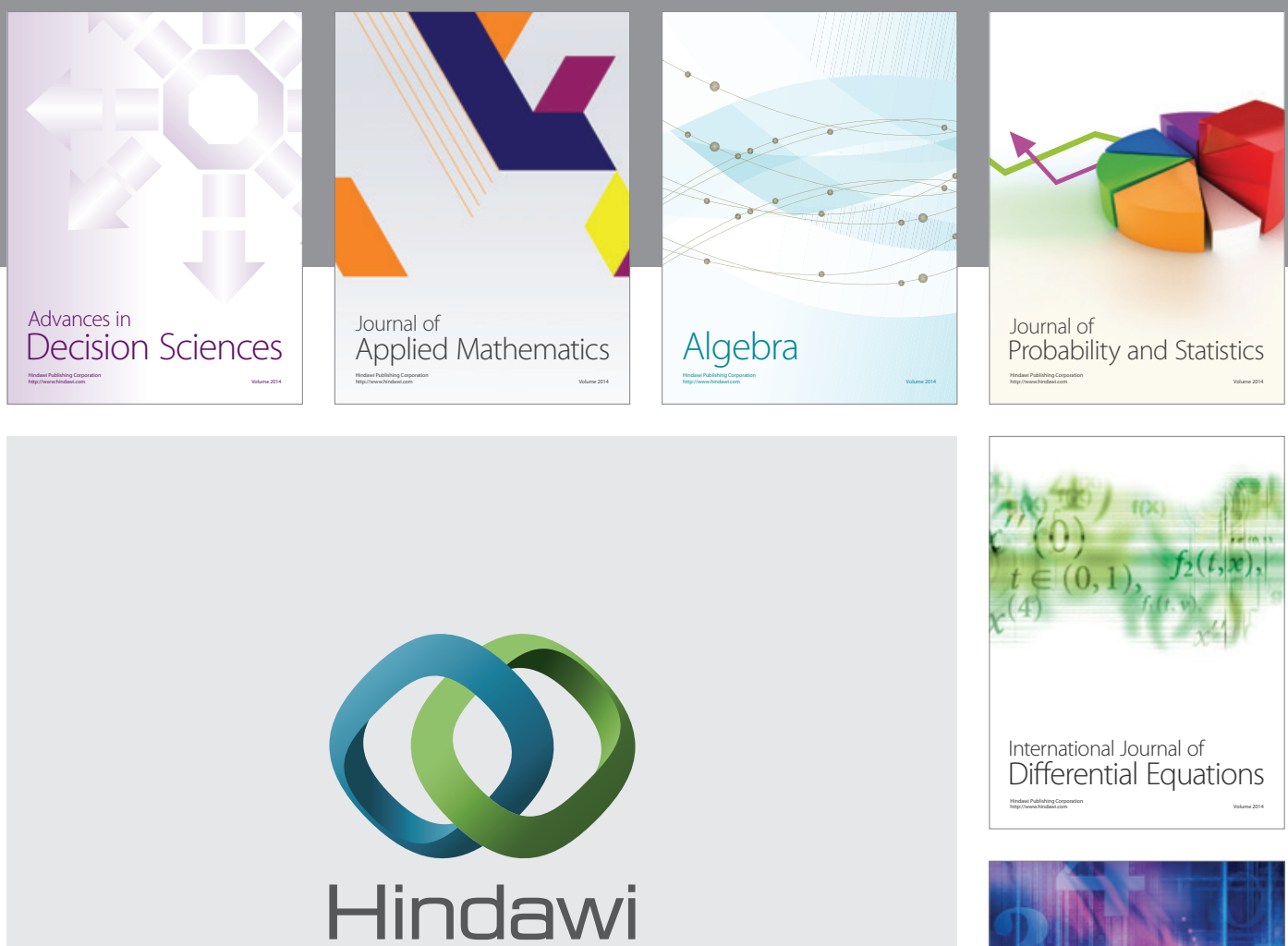

Submit your manuscripts at http://www.hindawi.com
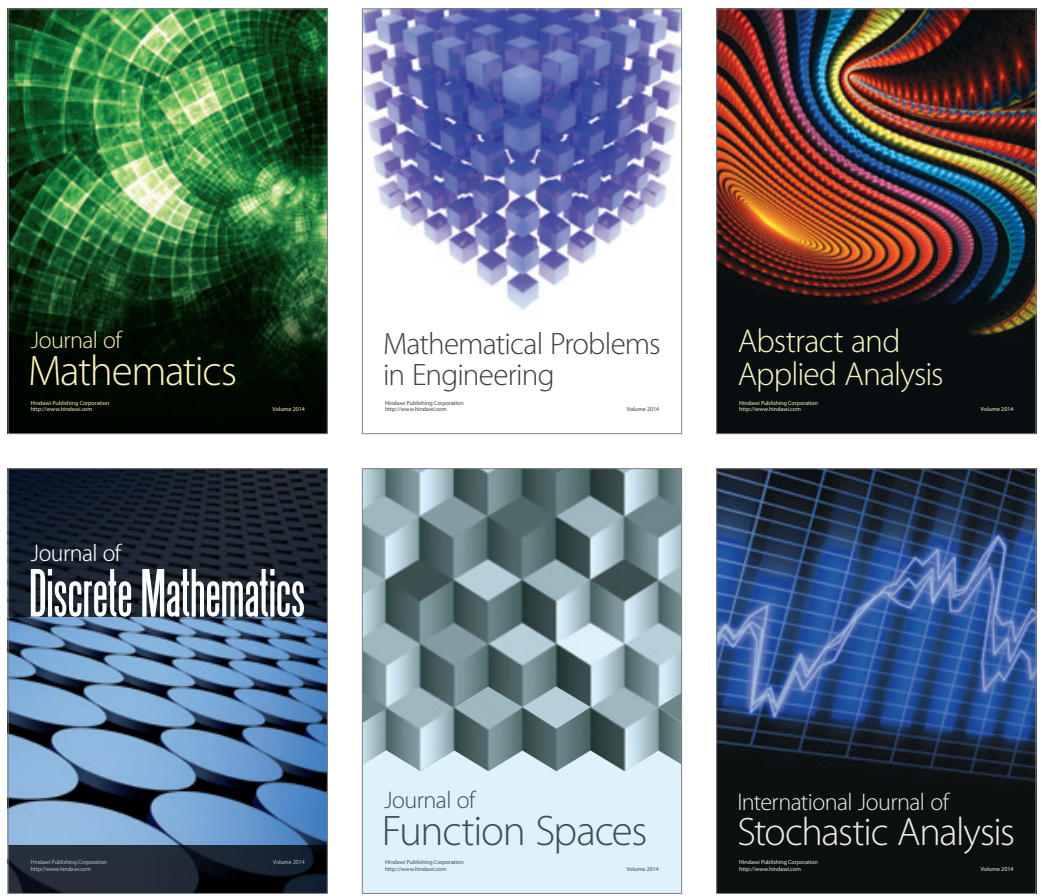

Journal of

Function Spaces

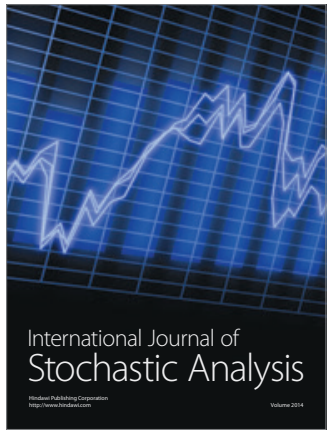

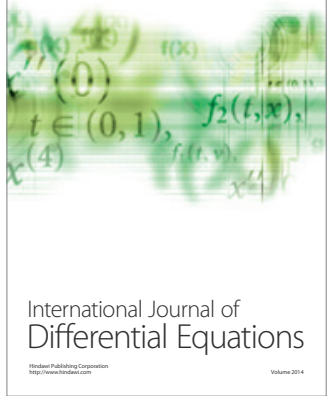
